\title{
DISCUSSION
}

\section{Soil consolidation associated with grouting during shield tunnelling in soft clayey ground}

\author{
K. KOMIYA, K. SOGA, H. AGAKI, M. R. JAFARI and M. D. BOLTON \\ (2001). Géotechnique 51, No. 10,835-846
}

\section{J. N. Shirlaw, Land Transport Authority, Singapore}

The authors have provided a very interesting paper, with a case study, laboratory testing and finite element analysis of the effects of grouting during EPB tunnelling. However, little detail is given on the monitoring and tunnelling in the case study, and further information would help to provide a fuller record of their work.

For the monitoring, were settlements measured using an array orthogonal to the direction of advance, to measure the width of the consolidation settlement trough? Based on my experience in Singapore with grout injected after tail void closure, I would expect the settlement troughs during consolidation for arrays B and C, and possibly A, to follow an 'error function' shape with a width similar to that of the initial settlement trough. Consolidation settlements due to this type of grouting have the effect of delaying the immediate settlement due to tunnelling, but the final effect is the same as immediate settlement. Using an $i$ value of half the depth to tunnel axis, this would imply that the total volume loss due to tunnelling was $5 \cdot 7 \%, 7 \cdot 5 \%$ and $7 \cdot 9 \%$ for cases $\mathrm{A}, \mathrm{B}$ and $\mathrm{C}$. These are relatively high values, but would be consistent with the closure of a gap of about $60 \mathrm{~mm}$ all around the tunnel. It would be useful to know the size of the tail void (the diameter cut by the machine minus the external diameter of the lining), to allow comparison with these volume loss figures.

The volume loss figures given above are high for an EPB machine operating in a firm clay. The stability number with no support pressure is $3 \cdot 49$. The total settlements recorded are high for such a stability number, even disregarding the support provided by the EPB machine. It would be useful to know the range of face pressures used during tunnelling, and whether the face was over-pressurised, which could lead to remoulding of the very sensitive clay.

The volume loss figures given above can also be expressed as volume losses of $0.405-0.558 \mathrm{~m}^{3} / \mathrm{m}$ of tunnel. Trials B and C involved the injection of 3.8 and $6 \mathrm{~m}^{3}$ of grout. Comparing these figures, I presume that the conventional tail void grouting was discontinued for several metres of the tunnel, but it is not stated over what length of tunnel the tail void grouting was replaced by the alternative grouting. This is important, because it appears that the settlement over Trials $\mathrm{B}$ and $\mathrm{C}$ was not just related to the effects of the trials. The surface settlement over the two trials would be due to the cumulative effects of tunnelling from a point about $21 \mathrm{~m}$ before the settlement point to about $21 \mathrm{~m}$ beyond the settlement point. It would therefore appear that the surface settlements over trials $\mathrm{B}$ and $\mathrm{C}$ would have included effects both from the trial injection and from the more conventional grouting as used in Trial A. I would note that the 'immediate' settlement identified in the paper does not allow for the time necessary for the full development of the immediate settlement trough, owing to this threedimensional effect.
The conventional tail void grouting appears to have been more effective than the trial injections at controlling total surface settlement. However, the settlement was still large for this size and type of machine operating in firm clay. The authors do not state whether the tail void grouting was carried out using grout pipes laid along the tail skin, to allow grouting simultaneously with machine advance, or through the lining. The former of these has been found to be much more effective at filling the tail void before it closes (in soft clays) than the latter.

I was very interested in the high compressibility of the cement/silicate grout (Type I) used, and the significant reduction in grout compression using the Type II grout. This is clearly an area that warrants further investigation. However, I would appreciate some clarification on some of the items in the paper. The authors report a $120 \mathrm{~s}$ gel-hardening time for the Type I grout, but for the identical grout used in the tunnelling trial report a $20 \mathrm{~s}$ gel time. In the consolidation testing of the grouts, the authors report that Type I lost $30 \%$ of its original volume 'after hardening'. I am not clear whether the $30 \%$ loss was measured on hardened grout, or during the interval between injection and hardening. I also note that with Type I grout the laboratory trials show an initial volume expansion of very close to $100 \%$ of the grout volume used in all but one case. For the Type II grout the initial volume expansion is well below $100 \%$ of the grout volume used in three out of seven cases, implying some other losses in the system. The authors also do not state the mix used for grouting in trial A: it would be useful to know whether this grout was also prone to significant loss of volume.

As a final comment, I question the normalisation of the grout volume by initial soil volume in Figs 10 and 12 . Within the laboratory trials the soil volume is defined by the size of the container. However, for wider application, this method of presentation is of limited value. Did the authors consider expressing the data in terms of $r+\ni r / r$, where $r$ is the radius of the initial injection cavity, and $r+\ni r$ is the radius of the expanding bulb (assuming expansion as a sphere)?

\section{Authors' reply}

The authors thank Dr Shirlaw for showing his interest in the paper. The trial was performed at a site owned by the client. Owing to space constraints, unfortunately it was not possible to measure settlements orthogonal to the direction of advance. The tail void gap was approximately $50 \mathrm{~mm}$ all around the tunnel: therefore the estimates made by Dr Shirlaw are reasonable.

The face pressure was set to be approximately $255 \mathrm{kPa}$. This value was determined by adding $20 \mathrm{kPa}$ to the total overburden pressure, which is standard practice in Japan. Because of this large pressure, it is possible that the clay in front of the machine was disturbed or remoulded, resulting 
in additional consolidation settlement. Unfortunately, there is no evidence to confirm this from the limited monitoring data.

Conventional tail void grouting was not performed when the alternative grouting method was employed. The distance of the section without tail void grouting was approximately $10 \mathrm{~m}$. When the tail void grouting was performed at Trial A, the monitoring points at $\mathrm{B}$ and $\mathrm{C}$ did not show any immediate settlements. However, the authors cannot confirm that the settlements at one trial site after some time were not affected by the grouting operations at the other trial sites. The data show only that Trials B and C generated larger settlements than Trial A, indicating an effect of grouting method (tail void grouting compared with alternative grouting).

No grout pipes were installed at the end of the shield machine. The tail void grouting was performed from either the first or the second lining placed outside the machine. The distance between the machine and the grouting point was about $30-50 \mathrm{~cm}$. This corresponds to a time lag of about $30 \mathrm{~min}$, allowing the gap possibly to close. Hence it is possible that this time lag has contributed to the large settlements observed.

In the experiment, the compressibility of the grout was evaluated separately from the grout injection tests. A given volume of grout was poured between heavily overconsolidated soil samples placed at the top and bottom of a large consolidometer. This was to create a more realistic soilgrout interface, which may affect the bleeding characteristics of grouts. After waiting for gel hardening, the composite soil-grout sample was consolidated at the same vertical pressure as used in the grout injection tests. With the knowledge of the compressibility of the overconsolidated soil sample, the volume loss of the grout due to vertical loading was measured and hence the compressibility of the grout was calculated. The $30 \%$ loss given in the paper comes from this test result.

Some initial loss observed in the Type II grout injection tests is due primarily to uncertainty in the amount of grout injected. The gel-hardening time of Type II was extremely short, and therefore it was not possible to measure the injected volume accurately. However, our experimental procedure has been improved since the presented work was performed, and injection volume is now determined more accurately. At present, grout efficiencies of close to $100 \%$ are obtained when grout is injected rapidly enough for the soil to be in undrained condition. The grout used in Trial A was a mixture of mortar and hardener; the volume reduction of this grout is considered to be small.

The authors do agree with Dr Shirlaw that the normalisations made in Figures 10 and 12 are not useful for practical application. In fact, a more extensive grout injection testing programme has been conducted at the University of Cambridge to investigate the effect of soil consolidation, grout properties, and injection method on grouting efficiency (Au, 2001), and these data are normalised in a similar manner to what Dr Shirlaw proposes.

\section{REFERENCE}

$\mathrm{Au}, \mathrm{S}$. K. A. (2001). Fundamental study of compensation grouting in clay. $\mathrm{PhD}$ thesis, University of Cambridge. 